\title{
Zinc inhibits apoptosis upstream of ICE/CED-3 proteases rather than at the level of an endonuclease
}

\author{
Chad M. Wolf ${ }^{1}$, Salvatore J. Morana ${ }^{1}$ and Alan Eastman ${ }^{1,2}$ \\ 1 Department of Pharmacology and Toxicology, Dartmouth Medical School, \\ Hanover, New Hampshire 03755, USA \\ 2 corresponding author: tel: (603)-650-1501; Fax: (603)-650-1129; \\ Email: Alan.Eastman@Dartmouth.edu
}

Received 28.10.95; revised 28.8.96; accepted 26.9.96

Edited by B.A. Osborne

\begin{abstract}
Apoptosis is commonly associated with DNA digestion, but it remains controversial as to which endonuclease is involved. The ability of zinc to inhibit DNA digestion in intact cells, and inhibit a $\mathrm{Ca}^{2+} / \mathrm{Mg}^{2+}$-dependent endonuclease in cell lysates, has been used frequently to suggest this is the endonuclease involved. However, zinc has many other effects on cells, and here it is shown that zinc also prevents many upstream events in apoptosis. These studies were performed in human ML-1 cells following incubation with etoposide. During apoptosis, these cells undergo intracellular acidification, increased accumulation of Hoechst 33342, DNA digestion and chromatin condensation. Zinc inhibited all of these events. An upstream event in apoptosis is activation of ICE/CED-3 proteases which is commonly observed as proteolysis of a substrate protein, poly(ADP-ribose) polymerase (PARP). The ICE/CED-3 proteases are themselves activated by proteolysis, and this was detected here by cleavage of one family member CPP32. Zinc prevented cleavage of both CPP32 and PARP. We recently demonstrated that dephosphorylation of the retinoblastoma susceptibility protein $\mathrm{Rb}$ was a marker of an event even further upstream in apoptosis; zinc was also found to inhibit $R \mathbf{R b}$ dephosphorylation. Therefore, zinc must protect cells at a very early step in the apoptotic pathway, and not as a directinhibitor of an endonuclease.
\end{abstract}

Keywords: apoptosis, zinc, $\mathrm{Ca}^{2+} / \mathrm{Mg}^{2+}$-dependent endonuclease, intracellular $\mathrm{pH}$, interleukin $1 \beta$ converting enzyme, CPP32 protease, $\mathrm{Rb}$

Abbreviations: ICE, interleukin $1 \beta$ converting enzyme; PARP, poly(ADP-ribose) polymerase; SDS, sodium dodecyl sulfate

\section{Introduction}

DNA fragmentation is probably a ubiquitous event in apoptosis, although the extent of fragmentation may vary between systems. In some systems, DNA fragmentation appears to be limited to 300 or 50 kilobase fragments, whereas in many systems, DNA fragmentation results in multimers of $\sim 180$ base pairs due to internucleosomal digestion of the chromatin-bound DNA (Walker et al, 1995). Whatever the extent of DNA digestion, identification of the endonucleases involved will facilitate understanding of the regulation of apoptosis. Many reports have suggested that the endonuclease is dependent upon $\mathrm{Ca}^{2+}$ and $\mathrm{Mg}^{2+}$ for activity and a variety of such endonucleases have been identified including deoxyribonuclease I (Peitsch et al, 1994) and cyclophilin (Montague et al, 1994). However, there are many examples of cells that do not exhibit the required increase in $\mathrm{Ca}^{2+}$ during apoptosis, or do not contain such an endonuclease. In our studies of apoptosis, we have identified deoxyribonuclease II which is active at decreased intracellular $\mathrm{pH}$ (Barry and Eastman, 1993). Furthermore, we have established that intracellular acidification consistently occurs during apoptosis (Barry and Eastman, 1992; Barry et al, 1993; Morana et al, 1994; Li and Eastman, 1995; Reynolds et al, 1996a). Recently, the occurrence of this intracellular acidification during apoptosis has been confirmed by other investigators (Perez-Sala et al, 1995; Rebello et al, 1995).

Although many endonucleases have been identified, their presence alone is inadequate to implicate them in apoptosis in intact cells, particularly when many cells express multiple endonucleases simultaneously. Zinc has been used frequently to implicate $\mathrm{Ca}^{2+} / \mathrm{Mg}^{2+}$-dependent endonucleases in apoptosis (Duke et al, 1983; Cohen and Duke, 1984; Ribeiro and Carson, 1993; Hughes and Cidlowski, 1994). Zinc is a well-known inhibitor of apoptosis in intact cells and also inhibits the $\mathrm{Ca}^{2+} / \mathrm{Mg}^{2+}$ dependent endonuclease in cell lysates. In contrast, deoxyribonuclease II is not inhibited by zinc (Barry and Eastman, 1993). We have previously expressed concern that zinc is not a specific inhibitor of the $\mathrm{Ca}^{2+} / \mathrm{Mg}^{2+}$ dependent endonuclease but can have many other effects on cells (Eastman, 1993, 1994; Morana et al, 1994). In this regard, we have reported that zinc can inhibit intracellular acidification in addition to DNA digestion (Morana et al, 1994).

Much recent evidence has focused on the identification of proteases of the ICE/CED-3 family that appear essential to the induction of apoptosis (Miura et al, 1993; Kuida et al, 1995; Tewari et al, 1995). Over-expression of these proteases will induce apoptosis, while inhibitors prevent apoptosis. These proteases are themselves activated by proteolytic cleavage. The intracellular activity of this protease family can also be assessed by the cleavage of an endogenous protein, poly(ADP-ribose) polymerase (PARP) (Lazebnik et al, 1994). We have recently established a temporal order of events in apoptosis in which dephosphorylation of the retinoblastoma susceptibility protein $\mathrm{Rb}$ occurs upstream of cleavage of PARP, DNA digestion and apoptosis (Morana et al, 1996). In the 
current experiments, we show that zinc prevents all of these events, demonstrating that the protective action of zinc is upstream of both $\mathrm{Rb}$ dephosphorylation and activation of ICE/CED-3 proteases and not at the level of an endonuclease. Hence, zinc can not be used to implicate any specific endonuclease in apoptosis, but may be of value in dissecting the upstream pathways of apoptosis.

\section{Results}

Many lymphoid cells undergo DNA digestion and apoptosis rapidly following a variety of insults. Human ML- 1 cells show chromatin condensation, DNA fragmentation and intracellular acidification within $4 \mathrm{~h}$ after a 30 min incubation with the topoisomerase II inhibitor etoposide (Morana et al, 1994, 1996). This time period has been used for the studies reported here. ML-1 cells were induced to undergo apoptosis with $20 \mu \mathrm{g} / \mathrm{ml}$ etoposide, and zinc sulfate was then added at various concentrations during the subsequent incubation. Partial inhibition of DNA digestion was observed at $0.1 \mu \mathrm{M}$ zinc, whereas a concentration of $1 \mathrm{mM}$ zinc produced almost complete inhibition of DNA digestion (Figure 1, top panel).

To determine the number of cells undergoing apoptosis, cells were analysed by flow cytometry for increased fluorescent staining with Hoechst 33342. A number of reports have shown that apoptotic cells accumulate Hoechst 33342 at an increased rate, and this can be assessed by a short incubation ( $<5 \mathrm{~min}$ ) with the dye (Dive et al, 1992; Ormerod et al, 1993; Li and Eastman, 1995). Simultaneously, cells were analysed for intracellular $\mathrm{pH}$ with the $\mathrm{pH}$-sensitive fluorescent ratio dye carboxy SNARF1. The results are visualized as a bivariate plot in which Hoechst fluorescence is shown on the ordinate and intracellular $\mathrm{pH}$ (expressed as the emission ratio of 545/ $640 \mathrm{~nm}$ ) is shown on the abscissa (Figure 2). Interestingly, we have found that these two fluorescent dyes detect exactly the same population of cells and, as a result, the combination of dyes helps to discriminate otherwise overlapping populations ( $\mathrm{Li}$ and Eastman, 1995; Morana et al, 1996; Reynolds et al, 1996b). The normal cells appear in the lower left quadrant and the majority of apoptotic cells in the upper right quadrant; the number of apoptotic cells is recorded in each panel.

Following incubation of cells with etoposide, $51 \%$ of the cells exhibited decreased intracellular $\mathrm{pH}$ (increased 585/ 640 ratio), and this population clearly exhibited enhanced Hoechst fluorescence (Figure 2). The addition of $1 \mathrm{mM}$ zinc eliminated the appearance of this population of cells. A concentration of $0.1 \mathrm{mM}$ zinc reduced the number of acidic cells to $16 \%$ consistent with the partial inhibition of DNA digestion. This flow analysis was performed while the extracellular $\mathrm{pH}$ was maintained at 7.1 , leading to an intracellular $\mathrm{pH}$ of 7.15 in the normal cells and 6.5 in the apoptotic cells.

Morphological changes detectable by staining with acridine orange were also investigated for each of these conditions. Control samples consistently showed less than $5 \%$ apoptotic cells whereas etoposide treatment induced chromatin condensation in $30-41 \%$ of the cells; the addition of $1 \mathrm{mM}$ zinc to etoposide-treated cells reduced

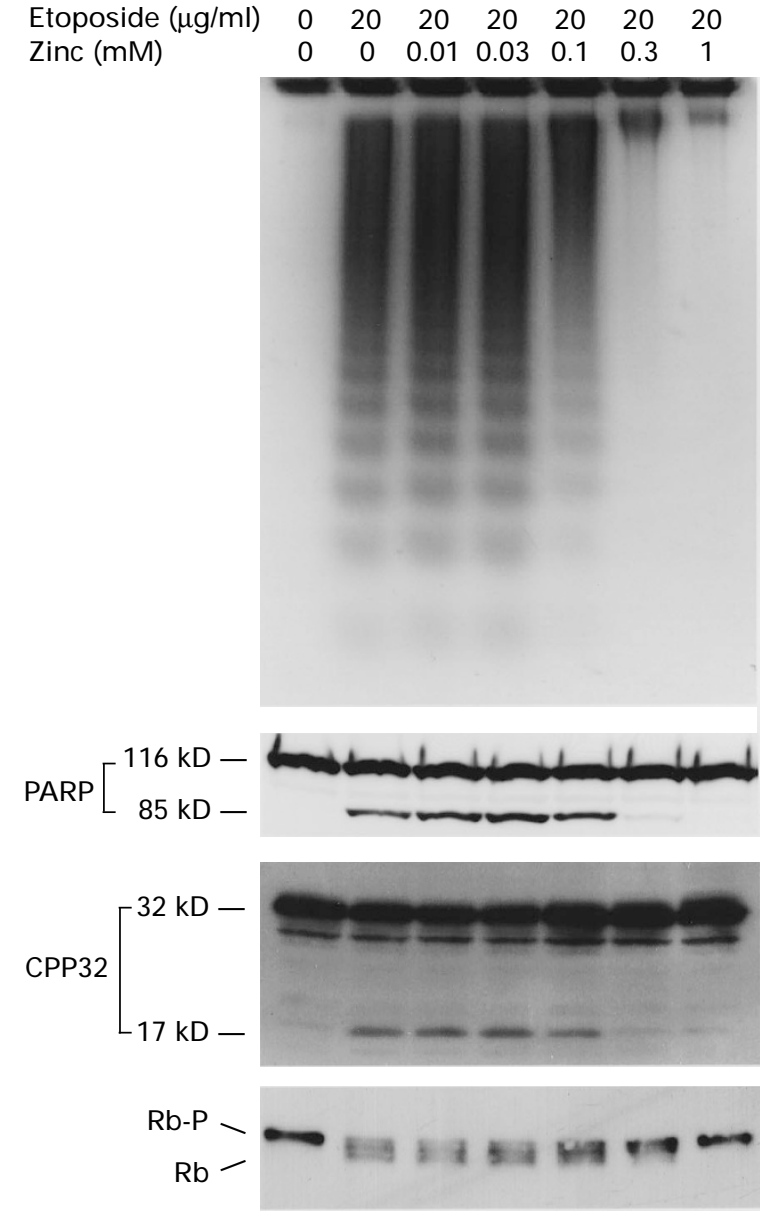

Figure 1 Zinc prevents DNA fragmentation, PARP cleavage, CPP32 cleavage and dephosphorylation of Rb. Cells were incubated with $20 \mu \mathrm{g} / \mathrm{ml}$ etoposide for $30 \mathrm{~min}$, the drug was removed and the cells incubated for an additional $4 \mathrm{~h}$ in the indicated concentrations of zinc sulfate. Cells were harvested and analysed for DNA fragmentation, proteolysis of PARP and CPP32, and the phosphorylation status of $\mathrm{Rb}$.

this value to $7.3 \%$ (average of three separate experiments). Hence, zinc was able to prevent apoptosis as assessed by chromatin condensation, increased Hoechst fluorescence and intracellular acidification, and this protection occurred at the same concentrations that also prevented DNA fragmentation.

We next determined whether zinc prevented cleavage of PARP. In undamaged cells, PARP electrophoreses as a single protein of $116 \mathrm{kDa}$ (Figure 1). Following incubation with etoposide, a new species appeared at $85 \mathrm{kDa}$ as expected from the activation of an ICE/CED-3 protease. This cleavage of PARP was inhibited above $0.1 \mu \mathrm{M}$ zinc which was the same concentration range that prevented DNA digestion. This result demonstrates that the protection afforded by zinc is either at or upstream of ICE/CED-3mediated proteolysis. To determine whether zinc inhibited the activation of ICE/CED-3 proteases, we investigated one family member, CPP32, whose activation can be judged by cleavage of the precursor $32 \mathrm{kDa}$. Following incubation of cells with etoposide, a cleavage product was detected at 


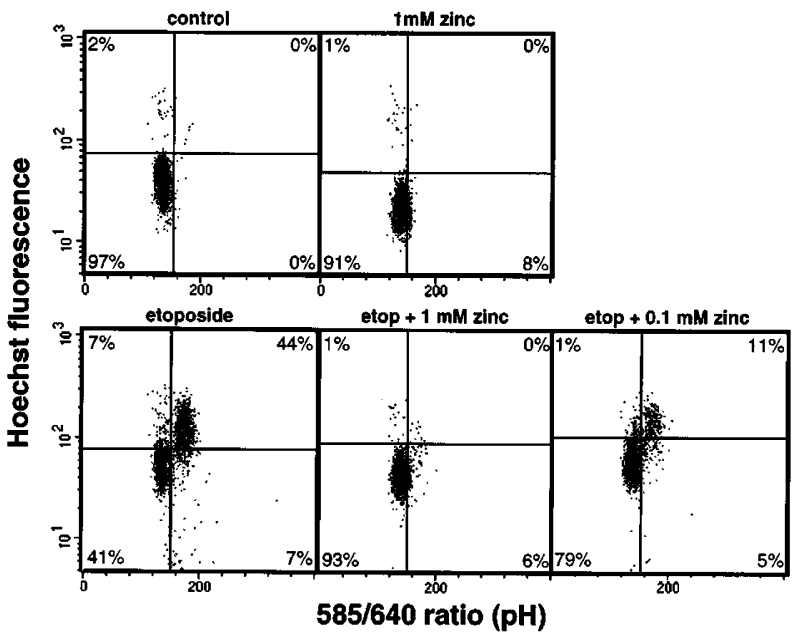

Figure 2 Zinc prevents the intracellular acidification and enhanced Hoechst fluorescence that occurs in ML-1 cells following incubation with etoposide. Cells were incubated without (top row) or with (bottom row) $20 \mu \mathrm{g} / \mathrm{ml}$ etoposide for $30 \mathrm{~min}$, the drug was removed, and the cells incubated for an additional $4 \mathrm{~h}$ in the indicated concentration of zinc sulfate. Cells were loaded with carboxy SNARF-1 during the final $1 \mathrm{~h}$, and Hoechst 33342 during the final $5 \mathrm{~min}$, and then analysed by flow cytometry. The $585 / 640$ ratio reflects intracellular $\mathrm{pH}$ and is contrasted to the Hoechst fluorescence. The cross-wires were drawn such that the majority of control cells appeared in the lower left quadrant; the vertical line $(\mathrm{pH})$ was maintained constant while the horizontal line was varied for each sample due to the variability inherent in loading cells with Hoechst 33342. The percentages shown reflect the distribution of cells in each quadrant.

$17 \mathrm{kDa}$ (Figure 1); this represents a catalytically active fragment (Schlegel et al, 1996). Incubation of cells with zinc prevented the cleavage of CPP32 at the same concentrations that prevented DNA digestion. Hence it appears that zinc protects cells by inhibiting the activation of at least one ICE/CED-3 family member.

We recently demonstrated that the retinoblastoma susceptibility protein $\mathrm{Rb}$ is dephosphorylated during apoptosis, and that this occurs upstream of the activation of ICE/CED-3 proteases (Morana et al, 1996). In undamaged ML-1 cells, Rb electrophoresed predominantly as a single hyperphosphorylated species (Figure 1). Following incubation with etoposide, a faster migrating band was observed that reflects the hypophosphorylated form of $\mathrm{Rb}$. Above $0.1 \mu \mathrm{M}$ zinc, this dephosphorylation of $\mathrm{Rb}$ was inhibited consistent with the concentrations that prevented DNA digestion. These results demonstrate that the protection afforded by zinc operates at or upstream of the phosphatase/kinase imbalance responsible for $\mathrm{Rb}$ dephosphorylation.

\section{Discussion}

Apoptosis is commonly associated with DNA digestion but many endonucleases exist which could be responsible (Eastman and Barry, 1992). Zinc can inhibit a $\mathrm{Ca}^{2+} / \mathrm{Mg}^{2+}$ dependent endonuclease in cell extracts, as well as inhibiting apoptosis in intact cells. This fact has been used frequently to suggest the involvement of a $\mathrm{Ca}^{2+} / \mathrm{Mg}^{2+}$-dependent endonu- clease in apoptosis (Duke et al, 1983; Ribeiro and Carson, 1993; Hughes and Cidlowski, 1994). However, we have previously shown that zinc can prevent DNA fragmentation in cells that appear to lack a $\mathrm{Ca}^{2+} / \mathrm{Mg}^{2+}$-dependent endonuclease, as well as inhibit intracellular acidification, suggesting that the action of zinc does not implicate any particular endonuclease in apoptosis (Morana et al, 1994). In this paper, we have further investigated the protection afforded by zinc.

The recent observations that proteases of the ICE/CED3 family are involved in apoptosis led us to determine whether the protection afforded by zinc was upstream or downstream of this proteolysis. PARP is commonly cleaved during apoptosis and it has been established that this can be mediated by the CPP32/Yama/apopain isoform of this protease family (Tewari et al, 1995; Nicholson et al, 1995). Other members of the ICE/CED-3 family may also be capable of cleaving PARP, but the prototype isoform ICE appears incapable in this regard (Lazebnik et al, 1994). Therefore, we assessed the cleavage of PARP as a marker for the activation of one of these proteases during apoptosis. The results showed that the cleavage of PARP correlated with the appearance of DNA digestion and chromatin condensation, and that zinc prevented DNA digestion, chromatin condensation and proteolytic cleavage of PARP. We also showed that CPP32 was cleaved to its active form during apoptosis and that zinc prevented this activation.

CED-3 was first identified as a protease essential for programmed cell death in C. elegans (Yuan et al, 1993). Subsequently, it was shown that specific inhibitors of ICE/ CED-3 proteases inhibit both cleavage of PARP and DNA digestion, confirming that activation of an endonuclease is downstream of an ICE/CED-3 protease in apoptosis (Tewari et al, 1995; Nicholson et al, 1995; Kuida et al, 1995). The observation that zinc inhibits CPP32 cleavage demonstrates that its action is at or upstream of the activation of this protease.

In related studies, we have shown that the retinoblastoma susceptibility protein $\mathrm{Rb}$ is dephosphorylated during apoptosis (Morana et al, 1996). Similar results have been reported in another system (Dou et al, 1995). Furthermore, this dephosphorylation was inhibited by several protein phosphatase inhibitors including okadaic acid and calyculin A (Morana et al, 1996). These inhibitors also prevented proteolysis of PARP, DNA digestion and chromatin condensation. The fact that zinc inhibited dephosphorylation of $\mathrm{Rb}$ suggests that its protective action is mediated at or upstream of the protein phosphatases and kinases responsible for $\mathrm{Rb}$ phosphorylation status. These experiments are beginning to establish a temporal relationship between a variety of regulators of apoptosis; specifically, a protein phosphatase activates an ICE/CED-3 isoform that subsequently leads to DNA digestion. This temporal order does not obviate the possibility that many intervening steps may occur between each of these events.

The target for the protective action of zinc is still unknown, but the results presented here demonstrate that it effectively inhibits dephosphorylation of $\mathrm{Rb}$, as well as cleavage of CPP32 and PARP. Given the temporal relationship between these events, we hypothesize that 
zinc functions to prevent the activation of ICE/CED-3 proteases via its ability, directly or indirectly, to modify a protein phosphatase or kinase whose activity is reflected in the dephosphorylation of $\mathrm{Rb}$. As discussed above, activation of ICE/CED-3 proteases has been established as a cause rather than a consequence of DNA digestion, and therefore zinc can protect cells at a very early step in the apoptotic pathway. It remains possible that zinc inhibits multiple steps in the apoptotic pathway, including direct inhibition of an endonuclease. However, since zinc clearly inhibits the pathway at an early step, the additional inhibition of an endonuclease is unnecessary for zincmediated protection. Therefore, the question of which endonuclease is invovled in apoptosis can not be resolved on the basis of sensitivity to zinc.

\section{Materials and Methods}

\section{Materials}

Carboxy-SNARF-1 AM was obtained from Molecular Probes (Eugene, OR). Other chemicals were obtained from Sigma Chemical Co. (St. Louis, MO). Cell culture supplies were purchased from Gibco/BRL (Grand Island, NY). The G3-245 anti-Rb antibody was purchased from Pharmingen (San Diego, CA), and the C-2-10 monoclonal antibody to poly(ADP-ribose) polymerase was a gift of Dr. Guy Poirier (Laval University Hospital, Quebec). The CPP32 polyclonal antibody was obtained from Dr. Donald Nicholson (Merck Frosst, Pointe ClaireDorval, Quebec).

\section{Cell culture}

ML-1 myeloid leukemia cells were maintained in $5 \% \mathrm{CO}_{2}$ at $37^{\circ} \mathrm{C}$ in RPMI 1640 medium supplemented with $10 \%$ fetal bovine serum, penicillin, and streptomycin. All cultures were maintained in logarithmic growth at a density $<1 \times 10^{6}$ cells $/ \mathrm{ml}$. Cells were incubated with etoposide for $30 \mathrm{~min}$ after which they were centrifuged, washed twice and resuspended in completed medium without drug. Zinc sulfate was added only for the $4 \mathrm{~h}$ incubation period following removal of etoposide.

\section{DNA fragmentation assay}

DNA digestion was measured by agarose gel electrophoresis as previously described (Barry and Eastman, 1993; Eastman, 1995). Briefly, $10^{6}$ cells were added directly to the wells of a $2 \%$ agarose gel, where they were lysed and digested with ribonuclease $A$ and proteinase $\mathrm{K}$. The gel was electrophoresed for $16 \mathrm{~h}$, and the DNA was stained with ethidium bromide and visualized under ultraviolet light. In this method, high molecular weight DNA (>20 kilobase pairs) remains trapped in or near the well, while smaller fragments (down to 180 base pairs) are resolved in the gel.

\section{Acridine orange staining}

Chromatin condensation in apoptotic cells was assessed by staining with acridine orange, while membrane integrity was measured simultaneously by exclusion of ethidium bromide (Duke and Cohen, 1992). A $25 \mu$ l aliquot of cells in medium was stained by addition of $1 \mu \mathrm{l}$ of a stock solution of $100 \mu \mathrm{g} / \mathrm{ml}$ acridine orange plus $100 \mu \mathrm{g} / \mathrm{ml}$ ethidium bromide in phosphate buffered saline. A minimum of 200 cells were scored under a fluorescence microscope for apoptotic morphology.

\section{Flow cytometry}

For the measurement of intracellular $\mathrm{pH}$, cells were loaded for $1 \mathrm{~h}$ with $1 \mu \mathrm{M}$ carboxy SNARF-1 acetoxymethyl ester, and analyzed on a Becton-Dickinson FACStar Plus flow cytometer with excitation at $488 \mathrm{~nm}$ and emission measured at $585 \mathrm{~nm}$ and $640 \mathrm{~nm}$ (Barry et al, 1993; Eastman, 1995). Cells were maintained at $37^{\circ} \mathrm{C}$ in complete medium including bicarbonate during analysis. The $\mathrm{pH}$ measurements were obtained by ratioing the fluorescence emissions at the two appropriate wavelengths, and comparing to a $\mathrm{pH}$ calibration curve.

Apoptotic cells were also detected by staining with Hoechst 33342 . This dye is thought to preferentially stain apoptotic cells due to very early changes in membrane permeability (Ormerod et al, 1993). Cells were incubated with $1 \mu \mathrm{g} / \mathrm{ml}$ Hoechst 33342 for $5 \mathrm{~min}$ and analyzed on the flow cytometer with excitation at $355 \mathrm{~nm}$ and emission measured at $440 \mathrm{~nm}$. In the experiments shown here, cells were stained with carboxy SNARF-1 for 55 min followed by the addition of Hoechst 33342 for 5 min prior to simultaneous analysis of the fluorescence of both dyes.

\section{Western blotting}

For analysis of PARP, $10^{6}$ cells were lysed by sonication on ice in $100 \mu \mathrm{l}$ of lysis buffer (50 mM Tris- $\mathrm{HCl}, \mathrm{pH} 6.8,4 \mathrm{M}$ Urea, $5 \% \beta$ mercaptoethanol, $2 \%$ SDS). $40 \mu \mathrm{l}$ of this lysate was electrophoresed on a $6 \%$ polyacrylamide/SDS gel (Miniprotean II; Bio-Rad, Hercules, $\mathrm{CA}$ ). The proteins were electroblotted to a polyvinylidene fluoride membrane (Immobilon-P, Millipore, Marlborough, MA), and blocked in TBSTM (50 mM Tris, pH 7.4, $150 \mathrm{mM} \mathrm{NaCl}, 0.1 \%$ (v/v) Tween-20, 5\% (w/v) Nonfat Dried Milk) for $2 \mathrm{~h}$ at room temperature. The membranes were probed with an anti-PARP mouse monoclonal antibody (C-2-10) diluted 1:10,000 in TBSTM. The goat anti-mouse secondary antibody (Bio-Rad) was diluted 1:3000 in TBSTM, and immunoreactivity was detected with the enhanced chemiluminescence detection kit (ECL, Amersham, Arlington Heights, IL).

For analysis of $\mathrm{Rb}, 10^{5}$ cells were lysed in $100 \mu \mathrm{l}$ of $50 \mathrm{mM}$ Tris$\mathrm{HCl}(\mathrm{pH} 6.8), 2 \%$ SDS, $0.1 \%$ bromophenol blue, $10 \%$ glycerol, $0.1 \% \beta$ mercaptoethanol; $20 \mu \mathrm{l}$ of this total cell lysate was electrophoresed in a $6 \%$ polyacrylamide/SDS gel. Proteins were electroblotted to membranes, blocked with $1 \%$ bovine serum albumin, and probed with anti-Rb mouse monoclonal antibody at a dilution of 1:1000. The goat anti-mouse secondary antibody was diluted 1:2000 and followed by ECL.

CPP32 was analysed by lysing $10^{6}$ cells in lysis buffer $(50 \mathrm{mM}$ Tris- $\mathrm{HCl}, \mathrm{pH} 6.8,2 \% \mathrm{SDS}, 2 \mathrm{mM}$ N-ethylmaleimide); $40 \mu \mathrm{l}$ of this lysate was electrophoresed on a $12 \%$ polyacrylamide/SDS gel. Proteins were electroblotted to a membrane, blocked in TBSTM, and probed with anti-CPP32 antibody in TBSTM diluted 1:10,000. The goat anti-rabbit secondary antibody was diluted 1:3000 in TBSTM and detection was by ECL.

\section{Acknowledgements}

The authors wish to thank Dr. Guy Poirier for providing the antibody to poly(ADP-ribose) polymerase, and Dr. Donald Nicholson for the antibody to CPP32. This study was supported by National Institutes of Health Grant CA50224. Flow cytometry was performed in the Herbert C. Englert Cell Analysis Laboratory supported in part by a Cancer Center Core Grant CA23108 to the Norris Cotton Cancer Center. 


\section{References}

Barry MA and Eastman A. (1992). Endonuclease activation during apoptosis: the role of cytosolic $\mathrm{Ca}^{2+}$ and $\mathrm{pH}$. Biochem. Biophys. Res. Commun., 186: 782-789

Barry MA and Eastman A. (1993). Identification of deoxyribonuclease II as an endonuclease involved in apoptosis. Arch. Biochem. Biophys., 300: 440-450

Barry MA, Reynolds JE and Eastman A. (1993). Etoposide-induced apoptosis in human HL-60 cells is associated with intracellular acidification. Cancer Res., 53: $2349-2357$

Cohen JJ and Duke RC. (1984). Glucorticoid activation of a calcium-dependent endonuclease in thymocyte nuclei leads to cell death. J. Immunol., 132: 38-42

Dive C, Gregory CD, Phipps DJ, Evans DL, Milner AE and Wyllie AH. (1992). Analysis and discrimination of necrosis and apoptosis (programmed cell death) by multiparameter flow cytometry. Biochim. Biophys. Acta, 1133: 275-285

Dou QP, An B and Will PL. (1995). Induction of a retinoblastoma phosphatase activity by anticancer drugs accompanies $P 53$-indpendent $G_{1}$ arrest and apoptosis. Proc. Natl. Acad. Sci. USA, 92: 9019-9023

Duke RC, Chervenak R and Cohen JJ. (1983). Endogenous endonuclease-induced DNA fragmentation: an early event in cell-mediated cytolysis. Proc. Natl. Acad. Sci. USA, 80: 6361-6365

Duke RC and Cohen JJ. (1992). Morphological and biochemical assays of apoptosis. In: Current Protocols in Immunology, Vol 1, JE Coligan, AM Kruisbeek, DH Margulies, EM Shevach and W Strober. eds. (New York: John Wiley and Sons), pp. 3.17.1-3.17.16

Eastman A and Barry MA. (1992). The origins of DNA breaks: a consequence of DNA damage, DNA repair or apoptosis. Cancer Invest., 10: 229-240

Eastman A. (1993). Apoptosis: a product of programmed and unprogrammed cell death. Toxicol. Applied Pharmacol., 121: 160-164

Eastman A. (1994). Deoxyribonuclease II in apoptosis and the signficance of intracellular acidification. Cell Death Different., 1:7-9

Eastman A. (1995). Assays for DNA fragmentation, endonucleases, and intracellular $\mathrm{pH}$ and $\mathrm{Ca}^{2+}$ associated with apoptosis. Methods Cell Biol., 46: 41-55

Hughes FM and Cidlowski JA. (1994). Apoptotic DNA degradation: evidence for novel enzymes. Cell Death Different., 1: 11-17

Kuida K, Lippke JA, Ku G, Harding MW, Livingston DJ, Su MS-S and Flavell RA (1995). Altered cytokine export and apoptosis in mice deficient in interleukin-1 $\beta$ converting enzyme. Science, 267: 2000-2003

Lazebnik YA, Kaufmann SH, Desnoyers S, Poirier GG and Earnshaw WC. (1994). Cleavage of poly(ADP-ribose) polymerase by a proteinase with properties like ICE. Nature, 371: 346-347

Li J and Eastman A. (1995). Apoptosis in an IL-2-dependent cytotoxic T lymphocyte cell line is associated with intracellular acidification: role of the $\mathrm{Na}^{+} / \mathrm{H}^{+}$-antiport J. Biol. Chem, 270: 3203-3211

Miura M, Zhu H, Rotello R, Hartwieg EA and Yuan J. (1993). Induction of apoptosis in fibroblasts by IL-1 $\beta$-converting enzyme, a mammalian homolog of the $C$. elegans cell death gene ced-3. Cell, 75: 653-660

Montague JW, Gaido ML, Frye C and Cidlowski JA. (1994). A calcium-dependent nuclease from apoptotic rat thymocytes is homologous with cyclophilin Recombinant cyclophilins A, B, and C have nuclease activity. J. Biol. Chem. 269: $18877-18880$
Morana S, Li J, Springer EW and Eastman A. (1994). The inhibition of etoposideinduced apoptosis by zinc is associated with modulation of intracellular $\mathrm{pH}$. Int. J. Oncol., 5: 153-158

Morana S, Wolf CM, Li J, Reynolds JE, Brown MK and Eastman A. (1996). The involvement of protein phosphatases in the activation of ICE/CED-3 protease, intracellular acidification, DNA digestion, and apoptosis. J. Biol. Chem., 271: $18263-18271$

Nicholson DW, Ali A, Thornberry NA, Vaillancourt JP, Ding CK, Gallant M, Gareau Y, Griffin PR, Labelle M, Lazebnik YA, Munday NA, Raju SM, Smulson ME, Yamin TT, Yu VL and Miller DK. (1995). Identification and inhibition of the ICE/CED-3 protease necessary for mammalian apoptosis. Nature, 376: $37-43$

Ormerod MG, Sun X-M, Snowden RT, Davies R, Fearnhead H and Cohen GM. (1993). Increased membrane permeability of apoptotic thymocytes: a flow cytometric study. Cytometry, 14: 595-602

Peitsch MC, Polzar B, Tschopp Jand Mannherz HG. (1994). About the involvement of deoxyribonuclease I in apoptosis. Cell Death Different., 1: 1-6

Perez-Sala D, Collado-Escobar D and Mollinedo F. (1995). Intracellular alkalinization suppresses lovastatin-induced apoptosis in $\mathrm{HL}-60$ cells through the inactivation of a pH-dependent endonuclease. J. Biol. Chem., 270: 62356242

Rebello A, Gomez J, de Aragon AM, Lastres P, Silva A and Perez-Sala D. (1995). Apoptosis induced by IL-2 withdrawal is associated with an intracellular acidification. Exp. Cell Res., 218: 581-585

Reynolds JE, Li J, Craig RW and Eastman A. (1996a). BCL-2 and MCL-1 expression in Chinese hamster ovary cells inhibits intracellular acidification and apoptosis induced by staurosporine. Exp. Cell Res., 225: 430-436

Reynolds JE, Li J and Eastman A. (1996b). Detection of apoptosis by flow cytometry of cells simultaneously stained for intracellular $\mathrm{pH}$ (carboxy SNARF-1) and membrane permeability (Hoechst 33342 ). Cytometry, (in press)

Ribeiro JM and Carson DA. (1993). $\mathrm{Ca}^{2+} / \mathrm{Mg}^{2+}$-dependent endonuclease from human spleen: purification, properties, and role in apoptosis. Biochemistry, 32 : $9129-9136$

Schlegel J, Peters I, Orrenius S, Miller DK, Thornberry NA, Yamin T-T and Nicholson DW. (1996). CPP32/Apopain is a key interleukin $1 \beta$ converting enzyme-like protease involved in Fas-mediated apoptosis. J. Biol. Chem., 271: 1841 - 1844

Tewari M, Quan LT, O'Rourke K, Desnoyers S, Poirier GG, Salvesen GS and Dixit VM. (1995). Yama/CPP32 $\beta$, a mammalian homolog of CED-3, is a CrmAinhibitable protease that cleaves the death substrate poly(ADP-ribose) polymerase. Cell, 81: 801-809

Walker PR, Pandey S and Sikorska M. (1995). Degradation of chromatin in apoptotic cells. Cell Death Different., 2: 97-104

Yuan J, Shaham S, Ledoux S, Ellis HM and Horvitz HR. (1993). The C. elegans cell death gene ced- 3 encodes a protein similar to mammalian interleukin- $1 \beta$ converting enzyme. Cell, 75: 641-652 